\title{
Giant Cell Tumor of the Temporal Bone Invading into the Pterygoid Muscle through the Temporomandibular Joint
}

\author{
Aboshanif Mohamed ${ }^{1}$ Kazuo Ishikawa ${ }^{1}$ Eigo Omi ${ }^{1}$ Kohei Honda ${ }^{1}$ Shinsuke Suzuki ${ }^{1}$ Teruyuki Sato ${ }^{1}$ \\ Naoko Fukui ${ }^{1}$ Masataka Takahasi ${ }^{2}$ \\ ${ }^{1}$ Departments of Otorhinolaryngology, Head and Neck Surgery, Akita \\ Graduate School of Medicine, Akita, Japan \\ 2 Departments of Neurosurgery, Akita Graduate School of Medicine, \\ Akita, Japan \\ Address for correspondence Kazuo Ishikawa, MD, Department of \\ Otolaryngology, Head and Neck Surgery, Akita University, School of \\ Medicine, 1-1-1, Hondo, Akita 010-8543, Japan \\ (e-mail: ishioto@med.akita-u.ac.jp). \\ J Neurol Surg Rep 2014;75:e136-e140.
Abstract
Keywords
- giant cell tumor
- temporal bone
- pterygoid muscle joint \\ - temporomandibular \\ We report a case of giant cell tumor of the temporal bone invading into the pterygoid \\ muscle through the temporomandibular joint. The patient was a 43-year-old woman \\ who developed left ear fullness 2 years earlier with a mass in the external auditory canal. \\ Radiologic evaluation revealed extension into the infratemporal fossa and confirmed \\ that the tumor was invading into pterygoid muscle. A middle cranial fossa approach \\ along with tympanoplasty was used for total resection of the tumor. Once a tumor \\ invades into muscle tissue, meticulous care is required to remove it because identifica- \\ tion of tumor tissue becomes extremely difficult.
}

\section{Introduction}

Giant cell tumor (GCT) is classified as a benign bone tumor, representing 4 to $9.5 \%$ of all bone tumors and $20 \%$ of all benign bone tumors. ${ }^{1}$ Although considered benign, GCT shows very aggressive behavior and a tendency toward both local recurrence and late malignant change with metastasis. These tumors predominantly arise in females, most frequently in the second and third decades of life. GCT originates from connective tissue within the bone marrow, and most commonly occur in the epiphysis of long bones. ${ }^{2}$ GCT usually arises in the epiphyseal or metaphyseal-epiphyseal region of the distal femur or proximal tibia, and sometimes in the distal radius; however, GCT in the skull is rare. ${ }^{3,4}$ A very small proportion of patients with GCT $(\sim 1 \%)$ may develop pulmonary metastases in addition to local bone destruction. ${ }^{5}$ We present the case of a middle-aged woman with GCT in the temporal bone at the left lateral skull base with invasion to the infratemporal fossa (pterygoid muscle) through the temporomandibular joint. Once this tumor invades into muscle tissue, identification of the tumor becomes extremely difficult.

received

December 4, 2013

accepted after revision

March 26, 2014

published online

May 28, 2014
DOI http://dx.doi.org/ $10.1055 / \mathrm{s}-0034-1376428$. ISSN 2193-6358.

\section{Case Report}

A 43-year-old woman was first seen in August 2011, complaining of left ear fullness that was first noticed 2 years earlier. Otolaryngologic examination revealed a mass in the left external auditory canal with no significant difficulty opening the mouth. An audiogram showed normal hearing on the right side and mixed hearing loss on the left side. The four-frequency pure tone average was $67.5 \mathrm{~dB}$, with an airbone gap of $45 \mathrm{~dB}$ (-Fig. 1A). Antibiotics were prescribed, but no improvement was noted.

Computed tomography (CT) showed a destructive mass in the temporal bone of the left lateral skull base with possible invasion into the temporomandibular joint, mastoid air cells close to the aperture of the mastoid antrum, and into the cranial cavity (-Fig. 2A, B). Biopsy from the external auditory canal mass was performed, revealing no malignancy. Gadolinium-enhanced magnetic resonance imaging (MRI) showed a nonenhancing mass in the left temporal bone. The patient then came to our department, and another biopsy from the external auditory canal mass was performed, again finding no
License terms

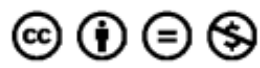

(c) 2014 Georg Thieme Verlag KG Stuttgart · New York 

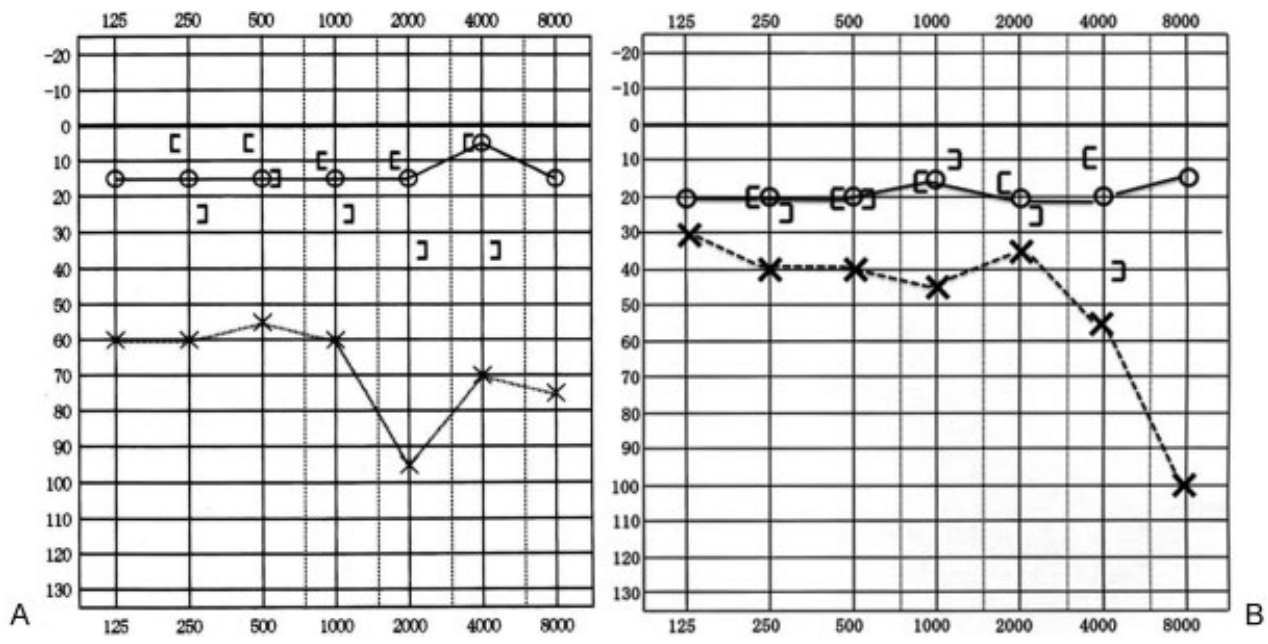

Fig. 1 (A) Preoperative pure tone average (PTA) showing normal hearing on the right side and left mixed-type hearing loss. The four-frequency PTA is $67.5 \mathrm{~dB}$ for air conduction with an air-bone gap of $45 \mathrm{~dB}$. (B) Postoperative PTA showing hearing improvement. The four-frequency PTA is $41.3 \mathrm{~dB}$ for air conduction with an air-bone gap of $21.7 \mathrm{~dB}$.
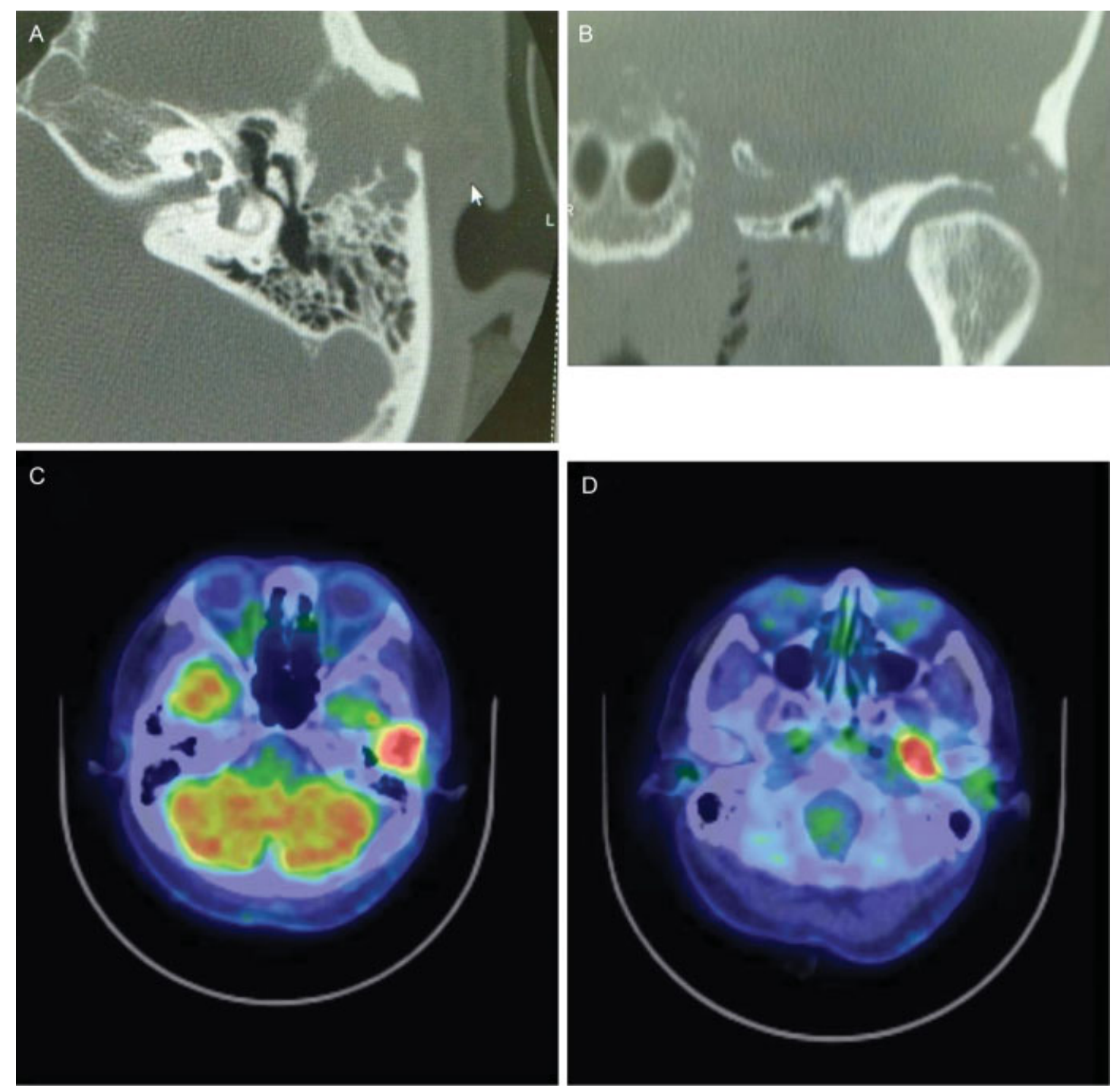

Fig. 2 Computed tomography (CT) and positron emission tomography (PET) show a mass in the left temporal bone. (A) Axial CT shows a soft tissue mass destroying the left lateral temporal bone with invasion close to the aperture of the mastoid antrum. (B) Coronal CT shows a mass in the left lateral skull base penetrating into the cranial cavity. (C) PET shows the upper part of the mass with high uptake (standardized uptake value [SUV]: 10) involving the left lateral temporal bone. (D) This also showed the lower part of the mass with high uptake (SUV: 7.8) involving the infratemporal fossa. 
malignancy. Positron emission tomography (PET) revealed a left temporal bone lesion in conjunction with an infratemporal fossa lesion (standardized uptake volume [SUV]: 10 and 7.8, respectively) (-Fig. $\mathbf{2 C}, \mathbf{D}$ ). The patient was found to be diabetic during routine preoperative investigation, so she was referred to the endocrinology department and insulin was prescribed. The patient was then hospitalized in our department to confirm the diagnosis and have the treatment policy determined. Open biopsy was performed from the preauricular region. Histopathologic examination showed that the lesion comprised multinucleated giant cells and a dense proliferation of spindle cells. The lesion also showed a mixture of histiocytes with phagocytosis of hemosiderin. No atypia or necrosis was evident (-Fig. 3A). Based on the histopathologic findings, GCT was finally diagnosed.

A left lateral temporal craniotomy using a middle cranial fossa approach along with tympanoplasty was performed for total resection of the tumor ( $\mathbf{- F i g . ~ 3 C ) . ~ A t ~ f i r s t , ~ c r a n i o t o m y ~}$ along the temporal line was undertaken. Mastoidectomy was then undertaken to ensure complete removal of the tumor. Intraoperatively, adhesions were identified between the tumor and dura of the middle cranial fossa, so the dura was resected and repaired using temporalis fascia and a Neoveil sheet (Gunze Limited Medical Division, Kyoto, Japan) under which the temporalis muscle flap was placed. However, the tumor was reddish brown and surrounded the temporomandibular joint with deep invasion into the pterygoid muscles as shown by histopathology ( - Fig. 3B). Accordingly, the condylar process was excised along with resection of the pterygoid muscle into which the tumor was invading. Because differentiating the tumor from muscle tissue was extremely difficult, tumor removal was carefully performed under magnification (-Fig. 3D). The dissected pterygoid space was filled with abdominal fat tissue. In addition, part of the tumor invading into the tympanic cavity and external auditory meatus and eroding the anterosuperior part of the canal wall with intact tympanic membrane was removed. The eroded bony wall was reconstructed using a piece of free cortical bone. Those parts of the tumor were also completely removed. Although the tumor was attached to the ossicular chain, articulation was fairly well preserved, and postoperative hearing was significantly better than before surgery (four-frequency pure tone average: $41.3 \mathrm{~dB}$ with an air-bone gap of $21.7 \mathrm{~dB}$; -Fig. 1B). As of the time of writing, 2 years postoperatively, no evidence of tumor recurrence has been identified.

\section{Discussion}

The clinical presentation in cases with GCT depends on the site of origin. Clinically, patients with GCT in the temporal
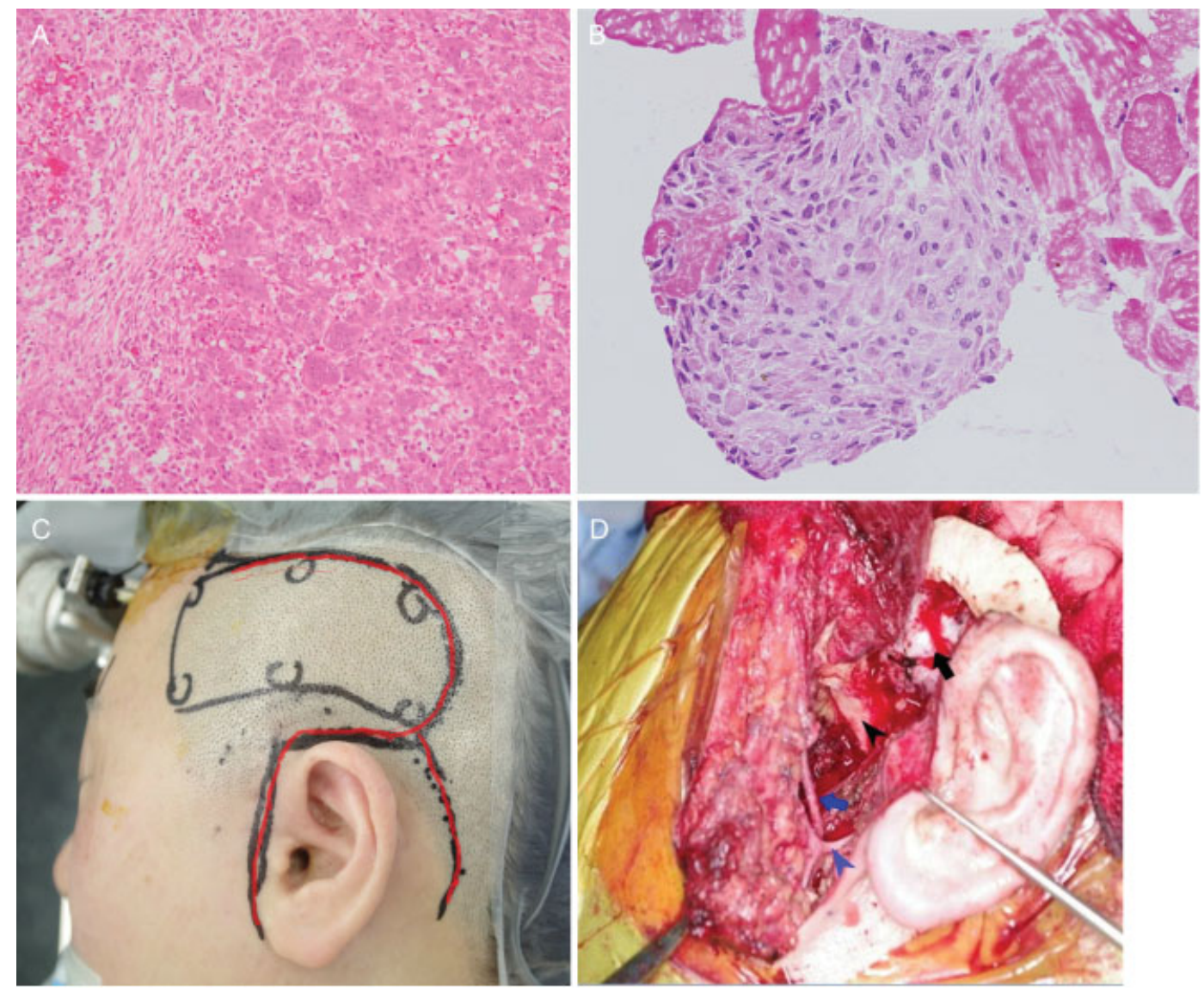

Fig. 3 (A, B) Histopathologic examination of the tumor specimen using hematoxylin and eosin staining showing (A) osteoclast-like giant cells with vesicular nuclei placed in a stroma of oval or spindle-shaped cells and (B) invasion of pterygoid muscles. (C) The incision line is marked in red, and the sites of burr holes for craniotomy are marked by black circles. (D) The surgical field: middle fossa dura (black arrow), cutting edge of the lateral skull base around the articular tubercle (black arrowhead), superficial temporal artery (blue arrow), and facial nerve trunk (blue arrowhead). 
bone typically display some degree of pain on the affected side, deafness, swelling in the affected region, and facial weakness, mostly in accordance with the site of tumor occurrence. ${ }^{6}$ Our patient showed ear fullness and a mass in the left external auditory canal, which was our guide in the diagnosis through biopsy. Considering the absence of the usual presentation of GCT and the unusual presentation with mass in the external canal, diagnosis of GCT without radiologic evaluation and biopsy was difficult.

Grossly, these tumors are gray to yellow-brown, soft, or firm and friable. Small cystic areas and gray-white necrotic foci may be seen. Microscopically, GCT consists of plump spindle-shaped or ovoid cells with admixed multinucleated, cytologically benign giant cells. Variable numbers of benign multinucleated cells are seen amid sheets of benign mononuclear spindle-shaped cells with similar nuclear features.
The nuclei are generally hypochromatic with inconspicuous nucleoli, and mitotic figures are uncommon. ${ }^{7}$

Plain radiography shows a radiolucent lesion of the skull that cannot be generally differentiated from other radiolucent lesions. On CT, GCT is seen as a lytic lesion expanding the bony cortex. These tumors are generally contrast enhancing due to their vascular nature. The tumors generally tend to expand and attenuate the bony cortex, rather than erode it. ${ }^{8}$ MRI of the tumor demonstrates signal isointensity on T1weighted imaging and signal hypointensity on both T2- and diffusion-weighted imaging, with the mass showing heterogeneous enhancement after intravenous gadolinium. ${ }^{9}$ In this patient, CT and MRI show an expansile mass of the temporal bone extending to the soft tissues of the infratemporal fossa with indistinct margins indicating aggressive behavior, and PET showed a high-uptake lesion.

Table 1 Previously reported cases of giant cell tumor of the temporal bone

\begin{tabular}{|c|c|c|c|c|c|}
\hline Study & Year & Age, y & Sex & Location & Operative approach \\
\hline Motomochi et al & 1985 & 38 & M & $\begin{array}{l}\text { Temporal base (epidural } \\
\text { space) }\end{array}$ & $\begin{array}{l}\text { Temporal craniectomy Y-shaped incision by } \\
\text { retroauricular approach }\end{array}$ \\
\hline Tandon et al & 1988 & 33 & $\mathrm{M}$ & $\begin{array}{l}\text { Temporosphenoidal } \\
\text { region }\end{array}$ & $\begin{array}{l}\text { Ablative surgery by Weber-Fergusson } \\
\text { approach }\end{array}$ \\
\hline McCluggage et al & 1995 & 31 & M & $\begin{array}{l}\text { Petrosquamous, infra- } \\
\text { temporal fossa }\end{array}$ & Preauricular approach \\
\hline Silvers et al & 1996 & 55 & $\mathrm{~F}$ & $\begin{array}{l}\text { Anterior portion of tem- } \\
\text { poral bone }\end{array}$ & Preauricular infratemporal fossa approach \\
\hline Li et al & 1997 & 36 & $\mathrm{~F}$ & Glenoid fossa & Preauricular middle cranial fossa approach \\
\hline Buter and Chilla & 1997 & 49 & $\mathrm{~F}$ & $\begin{array}{l}\text { Temporosphenoidal re- } \\
\text { gion, condylar fossa of } \\
\text { the mandibular joint }\end{array}$ & Retroauricular approach \\
\hline Omura et al & 1998 & 18 & $\mathrm{M}$ & $\begin{array}{l}\text { Glenoid fossa and } \\
\text { condyle }\end{array}$ & Preauricular approach \\
\hline Lee and Lum & 1999 & 45 & M & $\begin{array}{l}\text { Squamous, mastoid and } \\
\text { petrous portions }\end{array}$ & Sub- and transtemporal craniotomy \\
\hline Rosenbloom et al & 1999 & 33 & $\mathrm{~F}$ & Jugular foramen & Preauricular infratemporal fossa approach \\
\hline Gibbons et al & 2000 & 44 & M & $\begin{array}{l}\text { Petrous bone, glenoid } \\
\text { fossa, parotid and tem- } \\
\text { poralis muscle }\end{array}$ & Fisch type I \\
\hline Hilda et al & 2003 & 8 & $\mathrm{~F}$ & $\begin{array}{l}\text { Petrous and greater wing } \\
\text { of sphenoid }\end{array}$ & Radiotherapy \\
\hline Pai et al & 2005 & 26 & M & Petrosquamous & Preauricular approach \\
\hline Lee and Lee & 2006 & 31 & M & $\begin{array}{l}\text { Petrous bone, infratem- } \\
\text { poral fossa }\end{array}$ & Preauricular approach \\
\hline Wang et al & 2006 & 64 & $\mathrm{~F}$ & Petrosquamous, TMJ & Lateral temporal craniotomy \\
\hline Elder et al & 2007 & 2 & $\mathrm{~F}$ & Petrosquamous & $\begin{array}{l}\text { Preop, embolization and temporal } \\
\text { craniectomy }\end{array}$ \\
\hline Li et al & 2010 & 30 & $\mathrm{~F}$ & Squamous bone, TMJ & Preauricular approach, postop, radiotherapy \\
\hline Roberts et al & 2011 & 30 & M & $\begin{array}{l}\text { Temporozygomatic, in- } \\
\text { fratemporal fossa }\end{array}$ & Extended parotidectomy approach \\
\hline lizuka et al & 2012 & 32 & M & Middle ear, skull base & Transmastoid, middle cranial fossa \\
\hline Jain et al & 2012 & 41 & $\mathrm{M}$ & $\begin{array}{l}\text { Squamous, anterior pe- } \\
\text { trous bone }\end{array}$ & $\begin{array}{l}\text { Preoperative embolization, frontotemporal } \\
\text { craniotomy and debulking }\end{array}$ \\
\hline
\end{tabular}


The major radiologic differential diagnoses include aneurysmal bone cyst, chondroblastoma, dermoid cyst, chondrosarcoma, giant cell reparative granuloma, and pigmented

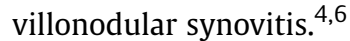

Surgical resection is the primary management choice. ${ }^{10}$ Many surgical approaches have been used for GCT in different portions of the temporal bone (-Table $\mathbf{1}$ ). In this case, the tumor invaded in a unique fashion from temporal bone to pterygoid muscle via the mandibular joint fossa. Once this tumor invades into muscle tissue, differentiation of tumor tissue from muscle is difficult. Accordingly, meticulous care was taken to remove the tumor under magnification. Careful follow-up of this case will be continued, although no evidence of recurrence has been seen.

The role of adjuvant radiotherapy in eliminating residual tumor tissue remains controversial. While considering the benign nature of the tumor and the possibility of malignant change with radiotherapy, surgical removal of the tumor represents the best treatment option, and en bloc resection is recommended to avoid recurrence. Radiotherapy remains the only option for unresectable tumors.

\section{Conclusion}

GCT of the temporal bone is a rare lesion, particularly with soft tissue invasion. Biopsy is the only sure method of diagnosis, and open biopsy may be needed to confirm the diagnosis. We have presented a case of GCT of the temporal bone with the unusual presentation of ear fullness and mass in the external auditory canal along with invasion into the infratemporal fossa. We performed lateral temporal craniotomy through a preauricular incision and mastoidectomy both to allow complete visualization of the infratemporal fossa and skull base and to ensure total resection of the tumor and thus reduce the recurrence rate. Our patient recovered with intact facial nerve function and improved hearing compared with before the surgery. Differential diagnoses include any destructive lesion of the temporal bone, and identification of tumor tissue is extremely difficult if invasion into muscle tissue occurs.

\section{Disclosure}

There is no financial support or funding to disclose.

\section{References}

1 Unni KK. Dahlin's Bone Tumors: General Aspect and Data on 11,087 Cases. 5th ed. Philadelphia, PA: Lippincott-Raven; 1996

2 Glasscock ME III, Hunt WE. Giant-cell tumor of the sphenoid and temporal bones. Laryngoscope 1974;84(7):1181-1187

3 Dahlin DC, Cupps RE, Johnson EW Jr. Giant-cell tumor: a study of 195 cases. Cancer 1970;25(5):1061-1070

4 Saleh EA, Taibah AK, Naguib M, et al. Giant cell tumor of the lateral skull base: a case report. Otolaryngol Head Neck Surg 1994;111(3 Pt 1):314-318

5 Campanacci M, Baldini N, Boriani S, Sudanese A. Giant-cell tumor of bone. J Bone Joint Surg Am 1987;69(1):106-114

6 Silvers AR, Som PM, Brandwein M, Chong JL, Shah D. The role of imaging in the diagnosis of giant cell tumor of the skull base. AJNR Am J Neuroradiol 1996;17(7):1392-1395

7 Wolfe JT III, Scheithauer BW, Dahlin DC. Giant cell tumor of the sphenoid bone. Review of 10 cases. J Neurosurg 1983;59:322327

8 Lee HJ, Lum C. Giant-cell tumor of the skull base. Neuroradiology 1999;41(4):305-307

9 Herman SD, Mesgarzadeh M, Bonakdarpour A, Dalinka MK. The role of magnetic resonance imaging in giant cell tumor of bone. Skeletal Radiol 1987;16(8):635-643

10 Roberts DS, Faquin WC, Deschler DG. Giant cell tumors of the temporal bone and infratemporal fossa: a case report and review of the literature. Laryngoscope 2010;120(Suppl 4): S180 